\title{
Controladoria: A relevância da Tecnologia da Informação na qualidade dos relatórios contábeis
}

\author{
Douglas Alexandre Sampaio de Lima ${ }^{1}$; Maria Erilúcia Cruz Macedo ${ }^{2}$
}

\begin{abstract}
Resumo: O presente trabalho busca apresentar a contribuição da tecnologia da informação diante da qualidade dos relatórios contábeis, pois com o desenvolvimento e evolução da tecnologia a contabilidade necessita está atualizando-se diariamente para atender à necessidade dos gestores de modo a auxilia-los diante das tomadas de decisões para obter vantagens competitivas diante dos demais concorrentes, visto que os consumidores estão cada vez mais exigentes na escolha de propostas vantajosas em suas compras. Deste modo buscou-se desenvolver os conceitos de sistemas de informações e suas funções paralelo a evolução da contabilidade através de pesquisa bibliográfica, descritiva e qualitativa em obras já publicadas sobre o tema. Portanto a tecnologia da informação possibilita que os relatórios contábeis possuam informações detalhadas da situação real das organizações eficazes e eficientes na tomada de decisão interna e externa.
\end{abstract}

Palavras chave: Tecnologia da informação, tomada de decisões, Evolução da contabilidade.

\section{Controllership: The Relevance of Information Technology in the quality of Accounting Reports}

\begin{abstract}
The present work seeks to present the contribution of information technology to the quality of accounting reports, since with the development and evolution of technology accounting needs to be updated daily to meet the need of managers in order to assist them in the competitive advantages vis-à-vis other competitors, as consumers are increasingly demanding to choose advantageous bids on their purchases. In this way, we tried to develop the concepts of information systems and their functions parallel to the evolution of accounting through bibliographical, descriptive and qualitative research in works already published on the subject. Therefore information technology enables accounting reports to have detailed information on the actual situation of effective and efficient organizations in internal and external decision making.
\end{abstract}

Key words: Information technology, decision making, Evolution of accounting.

\section{Introdução}

A tecnologia da informação está presente intensamente no século atual e a tendência é que haja uma evolução crescente da utilização de seus recursos, devido a necessidade e a dependência que a humanidade passou a ter por estas inovações tecnológicas, é comum

\footnotetext{
${ }^{1}$ Douglas Alexandre Sampaio de Lima, Concludente do curso de Ciências Contábeis, Universidade Doutor Leão Sampaio, E-mail: alexandredogulas357@gmail.com.

${ }^{2}$ Maria Erilucia Cruz Macedo, Bacharel do Curso de Ciências Contábeis Universidade Doutor Leão Sampaio, Brasil. E-mail: erilucia@leaosampaio.edu.br.
} 
diariamente observar em diversos setores da sociedade a implantação e utilização de recursos tecnológicos que auxiliem as atividades, estabelecendo comunicação.

Portanto, a contabilidade por ser uma ciência e ter como objetivo principal produzir informações sobre o patrimônio das entidades vem acompanhando esses avanços, por ser uma ferramenta que auxilia a contabilidade alcançar seu objetivo de produzir informações relevantes aos processos decisórios dos empresários, fazendo-se necessário a inclusão dos profissionais contábil diante deste ambiente tecnológico, a qual para manter-se atualizado é necessário a busca continua de conhecimentos e desenvolver habilidades para adequar-se a estas mudanças.

Todavia o principal objetivo da contabilidade é divulgar informações relevantes as empresas, com base nas suas atividades operacionais, além de fornecer periodicamente a posição patrimonial e financeira para que os usuários da informação contábil possam realizar a avaliação e definição da situação em que se encontra a entidade.

Com a tecnologia da informação a função da contabilidade destina-se além de atender as exigências legais e fiscais, passou a atuar como fonte de informações uteis a subsidiar a tomada de decisão dos gestores das organizações. Uma vez que surge esta relação a relação, os profissionais contábeis precisam atualizar-se constantemente sobre as ferramentas que a tecnologia da informação proporciona a contabilidade, para manter-se qualificado a estar incluso no mercado de trabalho.

Neste sentido, o uso das informações contábeis tornou-se indispensável diante do processo de tomada de decisões, uma vez que o mercado cada vez mais encontra-se competitivo no século XXI, tornando-se necessário o fornecimento de informações relevantes em tempo hábil para que possam subsidiar esta demanda.

Os recursos tecnológicos, associados a contabilidade, vem possibilitando cada vez mais mudanças significativas diante das organizações contábeis, devido ao fato das duas ciências estrem evoluindo paralelamente, possibilitando evoluções no fornecimento de informações cada vez mais relevantes aos gestores das entidades e os diversos usuários das informações contábeis.

Deste modo a tecnologia da informação passa a ser fundamental para o princípio de continuidade das atividades empresariais, por apresentar tamanha relevância e melhoria diante dos processos operacionais e decisórios das empresas, pincipalmente nas prestadoras de serviços contábeis, uma vez que aumenta a capacidade tecnológica dos softwares contábeis, os relatórios passam a ser mais qualificados, possibilitando as tomadas de decisões dos gestores e cooperando diretamente no desenvolvimento das organizações, possibilitando 
diferencial competitivo dos demais concorrentes que não conseguem se adaptar a essas evoluções tecnológicas.

A escolha do tema deu-se devido a percepção da importância da tecnologia da informação para a sociedade e todos os usuários da informação contábil. Portanto a pergunta de partida para o desenvolvimento do presente trabalho é: Qual a relevância da tecnologia da informação diante dos benefícios a qualidade das informações contidas nos relatórios contábeis? Referente a subsidiar os gestores diante da tomada de decisões nas organizações.

Tendo em vista a importância do tema a sociedade e a ciência contábil, o objetivo principal deste artigo é apresentar a relevância da tecnologia da informação na qualidade dos relatórios contábeis, justificando a sua escolha por ser um tema essencial diante da atualidade e ser uma ferramenta útil a contabilidade, além de se relaciona inteiramente no contexto socioeconômico nacional e internacional, pois com a globalização torna-se necessário cada vez mais relatórios bem elaborados e adequado as exigências mínimas das normas contábeis geralmente aceitas.

Assim sendo, o presente artigo busca especificamente; demonstrar a utilização da tecnologia da informação como ferramenta de desenvolvimento das atividades contábeis, analisar a qualidade das informações como suporte gerencial, verificar a adequação da tecnologia da informação a ciência contábil.

Para produção desse artigo, utilizou-se como base a revisão bibliográfica, em livros e artigos que referenciaram os conceitos e temáticas aqui abordadas.

Considera-se, portanto, que a tecnologia da informação contribui para que os relatórios contábeis possam oferecer informações detalhadas da situação real das organizações, contribuindo de forma eficaz na tomada de decisão dos gestores das entidades.

\section{A Tecnologia da Informação e seus Benefícios a Contabilidade}

A tecnologia da informação, remete-se a algo inédito, inexistente ou com capacidades elevadas de realizar procedimentos dos objetos que já são existentes, essa relação já se mostra benéfica ao ser humano, isto é quanto mais os indivíduos fazem novas descobertas eleva-se a capacidade tecnológica, favorecendo positivamente a qualidade de vida.

Tornou-se benéfica ao ser humano, pois busca dos indivíduos uma maior capacidade intelectual, uma vez que com as maquinas realizando suas atividades reduz consideravelmente 
a exigência da capacidade física, pois a demanda diante dos processos de trabalho passam a ser automatizados, estas substituem o esforço físico, exigindo capacitação e busca de conhecimento de ambos para se relacionarem adequadamente, deste modo a sociedade se beneficia, pois as pessoas possuirão capacidade intelectual elevadas capazes de desenvolver relações positivas (PINTO 2005).

\begin{abstract}
Quanto mais poderosas as máquinas, quanto maiores as energias libertadas, maio- res esforços intelectuais exigirão da parte do homem para dominar as colossais forças que começa a ser capaz de dirigir, para delas tirar os resultados desejados. Ao contrário do que muita gente diz, as máquinas não encerram seu papel ao liberta- rem o homem do esforço muscular, mas exatamente acarretam para ele a necessidade de mais intenso e difícil esforço intelectual para apoderar-se das possibilidades de ação útil nelas contidas e dar-lhes prosseguimento na produção de outras ainda mais eficientes (PINTO, 2005, p. 81).
\end{abstract}

Uma vez que é benéfica ao homem a tecnologia da informação passa a ser fundamental para todos os segmentos da sociedade. A contabilidade atualmente é um segmento que está diretamente ligada a ajuda dos computadores onde é perceptível nas organizações investimentos em softwares complexos ligados à área contábil. Assim sendo os sistemas de informação, são introduzidos para automação das tarefas repetitivas e estruturadas, evoluindo chegando ao ponto de produzirem informações pertinentes ao processo decisório gerencial e estratégico (GONÇALVES, RCM, RICCIO, 2009).

Segundo Iudícius (2015) a contabilidade é bastante antiga alguns historiadores tratam a existência das contas aproximadamente 2.000 anos a.C, porém o homem primitivo ao contar seus rebanhos, seus instrumentos de caça e pesca já estavam utilizando-se de forma rudimentar a contabilidade. É possível a localização destes exemplos no terceiro milênio antes de Cristo, em uma civilização da Suméria e da Babilônia, onde hoje está localizado o Iraque, esta evolução ocorreu lentamente até o surgimento da moeda, com a preocupação diante da riqueza e das propriedades o homem passou a buscar ferramentas para aperfeiçoar a avaliação do patrimônio.

Avançando no século XV com a divulgação da obra de Luca Pacioli na Itália surgiu a chamada "escola italiana", dominando em torno de vinte anos por toda a Europa, já no final do século XIX e começo do século XX com o desenvolvimento das grandes empresas e do mercado de capitais surgiu a "escola norte-americana" tornando mais ativo o papel da contabilidade e dos princípios contábeis, predominando a preocupação com os usuários da informação contábil buscando apresentar algo relevante para tomada de decisões (IUDICIUS, 2015).

No entanto o ambiente de negócios mudou com a Revolução Industrial, onde as empresas norte-americanas, através da grande produção de ferro com aumento da demanda, 
começaram a ocorrer a descentralização das entidades surgindo a necessidade de escoarem seus produtos e uniformizar a produção necessitando a inovação da administração e dos métodos de controle (SCHMIDT, SANTOS, MARTINS 2011).

Segundo Audy, Andrade, Cidral (2011) paralelamente a evolução da contabilidade, ocorria a evolução tecnológica que deu-se após o final do século XIX, pois vários pesquisadores desde o século XV estavam preocupados com a unificação da ciência e com as dificuldades diante dos problemas sociais, assim com o surgimento dos primeiros computadores, ferramenta esta que ao popularizar-se passou a colaborar com as atividades dos das entidades e dos contadores que tornaram-se os primeiros analistas das informações produzidas pelos sistemas das entidades.

Enaltecendo Hurt (2014) conceitua os sistemas de informações contábeis sendo o conjunto envolvendo documentos e tecnologias, propostos a coletar dados, processar e apresentar informações para dois grupos tomadores de decisões, dividindo-se em internos e externos. O autor destaca ainda que um sistema contábil bem projetado contribui consideravelmente diante do processo de tomada de decisões, facilitando a adequação ao atendimento aos padrões exigidos pela FASB (Financial Accounting Standards Board).

Deste modo as informações são composta por dados que se distinguem, onde os dados são os elementos em sua forma bruta, os dados pode ser percebidos na contabilidade como os eventos operacionais rotineiros, tais como compras e vendas de mercadorias, pagamento a fornecedores, recebimento de clientes dentre outros eventos, ou seja são a matéria-prima para as informações, porém isolados não conseguem explanar uma compreensão de determinada situação que são necessário o processamento obedecendo uma sequência lógica, surgindo a informação que é o dado trabalhado, assim obtendo as informações torna possível atender à necessidade dos usuários, que ao ter posse e compreensão, aos mesmos realizaram as suas tomada de decisões (OLIVEIRA, 2018).

Resende (2013) favorece que o processo de compartilhamento das informações produzidas pelos sistemas só é possível se os gestores e os demais usuários das informações, tais como clientes estiverem envolvidos ativamente com os recursos da tecnologia da informação, onde esse processo pode evoluir e os sistemas se encaixarem de diversas formas.

Um sistema contábil deveria ser capaz de produzir conjuntos básicos e padronizados de informações, com capacidade de atender a diversos usuários da informação contábil diante de suas necessidades mais urgentes (IUDÍCIUS,2015). 
Iudícius (2015) enaltece ainda que o objetivo básico da contabilidade em resumo é fornecer informações econômicas aos diversos usuários contábil, proporcionando decisões racionais, uma vez que o objeto da contabilidade em um sentido amplo vai além de um estudo de informações contábil financeira abrangendo outras áreas do conhecimento como a sustentabilidade e as áreas sociais.

No entanto as informações produzidas pelos sistemas devem ser apresentadas em tempo hábil aos usuários que necessitam dessas informações para tomada de decisões, se houver uma relação contraria a informação perde o fundamento reduzindo a capacidade de avaliação e controle (OLIVEIRA, 2018).

Para Chiavenato (2015) existe uma relação entre sistemas e informações, portanto a medida em que o volume de informações se eleva. Daí, faz-se necessário sistemas cada vez mais complexos e conhecimentos a seu respeito para elevar o nível de certeza, uma vez que a informação reduz as incertezas a respeito de um sistema.

Já para Padoveze (2010) as entidades devem lidar com as informações como qualquer produto disponibilizado ao consumo, sendo que os contadores diante dos sistemas devem elaborar informações para atender à necessidade dos outros, pois os sistemas de informações são amplos e devem atender toda a empresa. Este favorece o entendimento e a relação benéfica dos sistemas de informações em relação a contabilidade e as entidades.

Portanto, visto que os sistemas de informações proporcionam a contabilidade qualidades nas informações para tomada de decisões por parte dos usuários das informações contábeis, a contabilidade ganhou um novo espaço diante da tecnologia, pois através do avento dos sistemas de informações torna-se capaz a produção de relatórios com informações uteis e tempestivas que colaboram com o desenvolvimento das organizações, além de proporcionar diversas ferramentas inovadoras que facilitam a realização das atividades contábeis.

\section{A Contabilidade Gerencial E Sua Relação Com Os Sistemas De Informações Voltadas As Entidades}

A contabilidade vem se desdobrando diante dos avanços tecnológicos, pois as entidades necessitam cada vez mais de uma grande quantidade de informações para manter um diferencial competitivo no mercado em que estão inseridas, passando assim a exigir dos contabilistas suporte gerencial diante das demonstrações produzidas, ou seja o enfoque maior está na 
interpretação dos dados da empresa e de seu patrimônio para que haja a tomada de decisões (MARION, 2017).

Entretanto para Padoveze (2010, p.45) a contabilidade gerencial "Significa o conjunto de informações que tratam dos dados de forma aglutinada, para a visão dos grandes agregados empresariais. Devem ser números sintetizados, e os relatórios, concisos".

Em um sentido mais amplo, Marion (2017) conceitua a contabilidade gerencial como um sistema de informação que tem por objetivo suprir a entidade além de informações econômica, financeira, patrimonial, como também outras informações de natureza operacional, para que possa auxiliar os administradores nas suas tomadas de decisão.

Marion (2017) ainda destaca que a contabilidade gerencial surgiu simultaneamente a contabilidade de custos no ambiente industrial, onde se destaca por possuir papeis na entidade extra contábeis, devido à está relacionada também com operacionalidade das entidades para conhecer a realidade dos acontecimentos das entidades e produzirem informações uteis. Deste modo as ideias de ambos os doutrinadores acima citados se complementam, sendo que Marion, oportuniza a capacidade dos sistemas de informações gerenciais em subsidiar a administração das entidades na tomada de decisões.

Torna-se visível a percepção que para que haja qualidade na gerencia dessas informações para tomada de decisões, faz-se necessário a implementação de sistemas de informações que deem suporte suficiente aos administradores com o maior detalhamento possível de informações facilitando a interpretação, pois muitas vezes os mesmos não dispõe de tempo suficiente para analisar os relatórios que se não estiverem sintetizados e detalhados dificultaram a interpretação passando a ser inútil a informação diante do processo de gestão da entidade (REZENDE,2013).

Gordon, Gordon (2006) afirmam que os gestores podem utilizar-se de sistemas para obter informações de diversos agentes ligados a organização, tais como verificar o desempenho dos empregados, comunicar-se com outros gestores, tomar decisões gerir recursos dentre outras atribuições. Ressaltando que quanto maior elevar-se a demanda sobre estes sistemas, deverão ser mais sofisticados para satisfazerem as necessidades da informação com qualidade.

Os mesmos sistemas devem em um aspecto contemporâneo:

Diagnosticar necessidades de informação, avaliar a tecnologia da informação para atender estas necessidades e projetar sistemas de informações adequados formam a viga- mestra do desempenho efetivo no ambiente atual hoje. Até mesmo empresas bem geridas podem falhar como resultado de eventos não esperados ou de algumas decisões erradas. Bons gestores podem aumentar a probabilidade de sucesso de suas 
empresas usando informações para tomar boas decisões, motivar empregados e iniciar as mudanças necessárias. (GORDON, GORDON, 2006, p.11)

Em um mundo em tudo muda em instantes o segredo para manter-se competitivo está no acompanhamento em tempo real destas mudanças, uma vez que se destacará as entidades que se possível possam antecipar-se realizando adaptação as mesmas ao invés de reagirem a elas, pois em um mundo de negócios o cenário é bastante competitivo (CHIAVENATO, 2015).

A competição age forma positiva diante dos negócios, pois com a rivalidade a demanda busca sempre vantagem competitiva no mercado, onde a força competitiva de cada entidade vem dos seus recursos corporativos e essas forças devem estar sempre evoluindo, porém as empresas devem resguardar-se pois além das empresas existentes no mercado com a internet torna-se muito fácil o surgimento de novos empreendimentos que torna cada vez mais difícil de gerenciar (O'BRIEN, MARAKAS 2012).

O’Brien e Marakas (2012) destacam ainda que investimentos em tecnologia da informação fidelizam clientes e fornecedores, pois torna possível a utilização dos sistemas na melhoria da qualidade dos serviços pra os clientes, fornecedores e marketing, tornando-se valiosas prestes a impedi-los de substituir a empresa por seus concorrentes, porém devem estar buscando sempre projetos inovadores além de somente produzir reduzindo custos e despesas.

A contabilidade gerencial não deve ser entendida como um ramo da contabilidade financeira ou geral, deve ser considerada como uma necessidade que surgiu das organizações principalmente as que visão o lucro, de promover melhoria em seus produtos, bens ou serviços, pois os clientes estão na busca continua de preços baixos e produtos com mais qualidade (MARION, 2017).

O’Brien e Marakas (2012) então dar ênfase a valorização do consumidor, pois o preço deixou de ser única prioridade dos clientes, sendo que estão também interessados em qualidade, e recursos que agreguem valor aos seus produtos, assim sendo faz-se necessário atualização das organizações para com a preferência de seus clientes, as tendências de mercado, prestando então serviços personalizados que atendam às necessidades individuais de cada um, assim sendo as empresas que oferecerem esta concepção aos seus clientes consequentemente se destacaram no mercado.

Para obter sucesso as entidades devem modernizar seus sistemas gerenciais e operacionais que causem impacto positivo aos clientes e funcionários, criando comunidade entre ambos para que possam se comunicar estimulando a fidelização por parte dos consumidores (O'BRIEN, MARAKAS 2012). 
Portanto Chiavenato (2015) complementa que a informação gerencial para ser útil as organizações, não podem ser guardadas e isoladas dos usuários, deve ocorre a comunicação, ou seja deve ser transmitida e recebida para que possa alcançar seu objetivo, assim a comunicação pode ser entendida quando a informação torna-se comum a todos os envolvidos.

Já Padoveze (2010) busca a atenção dos contabilistas em relação aos planos de contas contábeis, diante dos sistemas de informações gerenciais, pois para que não tenham dificuldades em suas atividades futuras, é necessário quando for elaborar ter uma visão futurista das possíveis contas que possam surgir, além de criar contas adicionais para que quando haja a integração dos sistemas não haja muitas divergências, sendo que o plano de contas deve ainda proporcionar movimentações automáticas das contas e movimentações, isto possibilita a elaboração de relatórios automática envolvendo todos os assuntos necessários a elaboração dos relatórios na contabilidade gerencial.

Marion (2017) afirma que os contadores gerenciais são os responsáveis por subsidiar as entidades com informações em relação ao desenvolvimento e avaliar o que deve ser feito para que possam alcançar seus objetivos, portanto para que isto ocorra faz-se necessário engajamento com o pensamento dos gestores, além de estar ciente das finalidades da organização.

Complementando Marion (2017) destaca que as organizações devem buscar sistemas gerenciais que se adequem a suas atividades operacionais, pois os padrões de uma entidade, não servem de suporte para as outras, por possuírem características diferentes.

Já Resende (2013) esclarece que os sistemas de informações sendo informatizados ou não devem auxiliar os gestores a tomar decisões que favoreçam os objetivos das organizações, porém os informatizados estão relacionados ao negócio empresarial nas entidade privadas, se não conseguirem atender as necessidades e os objetivos de uma entidade, então a sua presença não será significativa a administração e ao funcionamento da organização.

O’Brien e Marakas (2012) enaltecem que investir em tecnologia facilita a empresa possuir oportunidades estratégicas, as vezes quando estes investimentos são em sistemas avançados torna capaz até a eficiência em seus processos organizacionais, além de possibilitar a produção de criação de novos produtos e serviços que se não houvesse esta capacidade tecnológica não seria possível.

Desta forma torna-se possível a compreensão que a contabilidade gerencial trata os sistemas de informações como uma ferramenta útil aos seus processos operacionais e de apoio aos clientes que estão cada vez mais em busca de produtos ou serviços com qualidade e com 
preços acessíveis, assim sendo faz-se necessário o entendimento das funções dos sistemas gerenciais dentro das organizações como ferramenta de suporte aos gestores na elaboração de relatórios gerenciais que são uteis a tomada de decisões.

\section{Funções dos Sistemas de Informações Gerenciais}

Diante dos avanços tecnológicos os sistemas de informações passaram a exercer alta relevância dentro das entidades, onde são alimentados pelos usuários das informações que assim captam, processam e armazenam esses dados gerando informações uteis para tomada de decisões. Portanto, para Oliveira (2014, p. 07) "Sistema é um conjunto de partes interagentes e interdependentes que, conjuntamente, formam um todo unitário com determinado objetivo e efetuam determinada função."

Assim sendo, percebe-se que os sistemas são como um conjunto de setores ou departamentos que realizam tarefas distintas, esses setores podem ser classificados como subsistemas, que nada mais é do que a fragmentação do objetivo principal em partes, onde cada subsistemas precisam dos demais para chegar a uma meta, ou seja possuem diferentes funções porém juntos conseguem alcançar um objetivo final, haja visto que os sistemas de informações gerenciais tem como objetivo final apresentar informações aos usuários. (GONÇALVES, RCM, RICCIO, 2009).

Para Padoveze (2010, p.48) os sistemas são classificados em:

\footnotetext{
Os sistemas classificam-se em sistemas abertos e fechados. Os sistemas fechados não interagem com o ambiente externo, enquanto que os sistemas abertos caracterizam-se pela interação com o ambiente externo, suas entidades e variáveis. Existem sistemas físicos e sistemas informacionais. A empresa é um sistema aberto, bem como os sistemas de informações, pois há um processo de interação com o ambiente.
}

Este favorece a relação existente entre os sistemas e a empresa encaixando a predominância em que a mesma está inserida, diferenciando os tipos de sistemas de informações existentes, levando em consideração desde o ambiente interno que é composto dos administradores e colaboradores até o ambiente externo constituído dos demais elementos necessários para o funcionamento da entidade, tais como clientes, bancos, fornecedores, etc.

Segundo O’Brien e Marakas (2012) qualquer associação organizada de pessoas, hardwares que são as partes físicas ou palpável dos computadores, softwares que são toda a 
parte lógica ou intangível dos computadores e as redes de comunicação são capazes de transformar e divulgar informações dentro das organizações.

Quanto a divisão dos sistemas nas organizações públicas e privadas, distinguem-se apenas diante do enfoque, pois nas privadas estão voltados ao negócio empresarial, já nas públicas está voltada as atividades principais, são semelhante em ambos os tipos de organizações os seus objetivo, que compreendem basicamente em auxiliar nos processos decisórios (RESENDE, 2013).

Complementa O’Brien e Marakas (2012) que embora haja diversas aplicações para os sistemas de informação existem três papeis essenciais exigidos por as empresas que os sistemas de informações são capazes de realizar sendo eles: Suporte de operação de negócios; Suporte a tomada de decisões pelos empregados e gerentes; Suporte das sus estratégias para vantagem competitiva.

Diante do suporte a operação de negócios os sistemas de informações coopera com a entidade no momento da realização de suas tarefas operacionais rotineiras, tais como cadastra clientes, vendas compras dependendo do ramo de atividade da empresa, já diante do suporte a tomada de decisões por parte dos empregados e gerentes, é o momento em que ao cadastrar as informações os mesmos terão em mãos informações uteis para analisar a demanda, custos, despesas corrigindo os erros e enaltecendo as qualidades dos seus produtos ou serviços, com isso em seu terceiro e último papel o sistemas ajudaram consequentemente as organizações a manter-se competitiva no mercado em que estão inseridas.

Ou seja, uma vez que sistemas de informações gerenciais são planejados a cooperar com os processos operacionais simultaneamente podem fornecer dados aos gestores para tomada de decisões. As empresas atuais cada vez mais estão buscando integração de seus sistemas com a finalidade de permitir um fluxo livre de informações flexíveis a dar suporte aos negócios.

Ressalta Oliveira (2018, p.33) que para as empresas conseguirem obter as vantagens dos sistemas de informações é necessário observar algumas premissas tais como:

\footnotetext{
i) Envolvimento adequado da alta e média administração com o SIG. (...)

ii) Competência por parte das pessoas envolvidas no SIG. (...)

iv) Atenção específica ao fator humano da empresa. (...)

v) Habilidade dos executivos da empresa em identificar a necessidade de informações.

(...)

vi) Habilidade dos executivos da empresa em tomar decisões com base em informações. (...)

(...)

x) Conhecimento e confiança no sistema de informações gerenciais. (...)

xi) Existência de dados e informações relevantes e atualizados. (...).
} 
Na visão de Chiavenato (2015) as empresas devem possuir planejamento e estrutura antecipadamente para que os sistemas de informações gerenciais possam alcançar seus objetivos com excelência sem que haja improvisação, buscando sempre realizar as atividades com eficácia afim de alcançar a eficiência podendo assim chegar a resultados superiores aos esperados.

Para que os sistemas de informações possa obter um papel ativo dentro das organizações, faz-se necessário suporte da gerencia da organização, uma vez que os sistemas de informações gerenciais devem comtemplar toda a empresa e ser capaz de produzir relatórios planejados envolvendo os conteúdos com os mesmos níveis de informações dos usuários em que se destina (PADOVEZE,2010).

As entidades beneficiam-se dos sistemas de informações, quando conseguem reduzir seus custos, agregam valores aos seus produtos, administrar a carga de trabalho dos funcionários e elevam a eficácia e a eficiência operacional (REZENDE,2013).

Deste modo os gerentes necessitam de informações em tempo real sobre as atividades operacionais, resultados positivos ou negativos, essas informações são subsidiadas pelos sistemas de informações gerenciais que oferecem aos gestores redução dos custos além do aproveitamento dos recursos físicos e tecnológicos (MARION,2017).

Ainda Marion (2017) descreve que os clientes cada vez mais estão em busca de serviços e produtos com preços acessíveis mantendo sempre um padrão de qualidade, assim para que as empresas possam estar sempre inovando para atender esta demanda sem prejuízos é necessário sempre a busca continua da redução dos custos, trabalhando sempre em busca da eficiência em suas atividades operacionais, sabendo que esta relação acontece no mercado em que estão inseridas as organizações junto os gestores devem buscar sempre informações uteis a tomada de decisões através dos relatórios produzidos pelos sistemas de informações gerenciais.

Os sistemas estão promovendo um novo ordenamento diante da globalização, pois além da tomada de decisões permitem o processamento, arquivamento e divulgação dos dados da entidade em um formato dinâmico e ágil, sendo que quanto maior for o nível informacional dos clientes e usuários das informações contábeis maior é a necessidade de as entidades estarem preparadas com informações uteis, uma vez que as informações movem as entidades a chegarem ao seus objetivos e alcançarem o sucesso ( CHIAVENATO, 2015).

Portanto, percebe-se que para que os sistemas de informações consigam realizar suas funções dentro das organizações os gestores e colaboradores devem estar preparados para não realizem investimentos com um custo maior que seus benefícios para a entidade, e para que 
esses investimentos possam gerar retornos esperados a alta administração, assim capacitando seus colaboradores para que possam desfrutar de todas as funções dos sistemas de informações gerenciais, diante da produção e entendimento das informações contidas nos relatórios, devendo ser exatos para atender os prazos esperados pelos gestores para subsidiar a tomada de decisões.

\section{Metodologia da Pesquisa}

O presente trabalho trata-se de pesquisa bibliográfica baseada em obras já publicadas tais como livros, artigos científicos, revistas sobre assuntos como a Evolução e Relevância da Tecnologia da Informação, Controladoria Estratégica, Evolução da Contabilidade dentre outros correlatados.

Apresenta característica descritiva na busca de descrever a relevância da tecnologia da informação na qualidade dos relatórios contábeis, que de acordo com Gil (2017, p.25) "as pesquisas descritivas, tem como objetivo a descrição das características de determinada população ou fenômeno".

Tem uma abordagem qualitativa, pois trata-se de pesquisa com enfoque interpretativo das obras já publicadas a respeito do tema em estudo, deste modo Marconi e Lakatos (2017, p.313) descreve que pesquisa qualitativa "é uma técnica de coleta de dados que tem como objetivo explorar e descrever fenômenos, ambientes, aspectos da vida social de um grupo".

\section{Considerações Finais}

A tecnologia da informação assumiu uma função essencial nas organizações e nos escritórios contábeis, pois possibilitou mudanças distintas no comportamento dos profissionais contábeis, que necessitam atualmente possuir uma visão ampla das relações exigidas com a globalização, com estas evoluções cada vez mais está sendo possível obter informações em tempo real e compreensivas.

Considerando a importância dos sistemas de informações diante da elaboração de relatórios contábeis, o presente trabalho possibilitou analisar a relação benéfica dos sistemas a contabilidade diante da produção de relatórios com informações relevantes, além das diversas ferramentas que auxiliam os gestores a tomarem decisões racionais, dentro da perspectiva de 
evitar e corrigir erros, desperdícios e atender aos consumidores de modo que haja a fidelização em um mercado bastante competitivo, assim como a avaliação da evolução da contabilidade paralelamente aos sistemas de informações que passaram a possuir características gerenciais.

Porém, é importante entender que tecnologia da informação apenas processa os dados em relação as necessidades definidas pelos usuários das informações diante dos sistemas contábil e gerencial, mas a reponsabilidade para que as operações sejam desenvolvidas corretamente e de acordo com as normas contábeis geralmente aceitas é dos contabilistas, que comprometem então o desenvolvimento do processo decisório dos gestores e usuários quando não apresentam informações tempestivas e fidedignas. Outro fator que impede a eficiência é a falta de qualificação dos contabilistas, gestores e colaboradores das organizações, que se não estiverem qualificados, não alimentaram os sistemas corretamente, além de não aproveitar todos os recursos disponíveis.

Acredita-se que os resultados deste estudo possam contribuir para confirmar então a relevância dos sistemas de informações diante da qualidade dos relatórios contábeis e ainda sua eficácia e eficiência diante do processo de informação para a tomada de decisões dos gestores das organizações, evitando erros que comprometam sua finalidade.

Portanto, cabe aos contadores, utilizar adequadamente as ferramentas que a tecnologia da informação proporciona a contabilidade, utilizando de modo eficiente todos os recursos disponíveis que auxiliem a produção dos relatórios contábeis.

\section{Referências}

AUDY, Jorge Nicolas, ANDRADE, Gilberto de, CIDRAL, Alexandre. Fundamentos de Sistemas de Informação. Porto Alegre: Bookman, 2011. Disponível em: https://integrada.minhabiblioteca.com.br/\#/books/9788577801305/. Acesso em: 09 Set. 2018.

CHIAVENATO, Idalberto. Iniciação um Sistemas, e Métodos Organização - SO \& M. São Paulo: Manole, 2015. Disponível em: https://integrada.minhabiblioteca. com.br/\#/books/9788520442838/. Acesso em: 10 Set. 2018.

GIL, Carlos, A. Como Elaborar Projetos de Pesquisa. $6^{a}$ ed. São Paulo: Atlas, 2017. Disponível em: https://integrada.minhabiblioteca.com.br/\#/books /9788597012934/cfi/6/60!/4@0:0. Acesso em: 25 Out. 2018.

GONÇALVES, Grillo, RCM, RICCIO, Luiz, E. Sistemas de informação. São Paulo: Atlas, 2009.Disponível em: https://integrada.minhabiblioteca.com.br/\#/books/9788522471232/. Acesso em: 15 Set. 2018. 
GORDON, Steven R., GORDON, Judith R. Sistemas de Informação - Uma Abordagem Gerencial, $3^{\mathrm{a}}$ ed. Rio de Janeiro: LTC, 2006. Disponível em: https://integrada. minhabiblioteca.com.br/\#/books/97885-216-2391-5/. Acesso em: 20 Set. 2018.

HURT, Robert L. Sistemas de Informações Contábeis, $3^{\text {a }}$ ed. Porto Alegre: AMGH, 2014. Disponível em: https://integrada.minhabiblioteca.com.br/\#/books/9788580553314/. Acesso em: 25 Set. 2018.

IUDÍCIBUS, Sérgio de. Teoria da Contabilidade, 11ª ed. São Paulo: Atlas, 2015.

Disponível em: https://integrada.minhabiblioteca.com.br/\#/books/9788522496242/. Acesso em: 28 Set. 2018.

MARCONI, Marina Andrade, LAKATOS, Eva Maria. Metodologia Científica, $7^{\mathrm{a}}$ ed. São Paulo: Atlas, $2017 . \quad$ Disponível em: https://integrada. minhabiblioteca.com.br/\#/books/9788597011845/cfi/6/32!/4/182@0:14.0. Acesso em: 25 Out. 2018.

MARION, José Carlos. Introdução à contabilidade gerencial, $3^{a}$ ed. São Paulo: Editora Saraiva, 2017. Disponível em: https://integrada.minhabiblioteca .com.br/\#/books/9788547220891/. Acesso em: 30 Set. 2018.

O'BRIEN, James A., MARAKAS, George M. Administração de Sistemas de Informação. Porto Alegre: $\quad 2012.2$ Disponível em: https://integrada. minhabiblioteca.com.br/\#/books/9788580551112/. Acesso em: 30 Set. 2018.

OLIVEIRA, Djalma de Pinho Rebouças de. Sistemas de Informações Gerenciais, $16^{a}$ ed. São Paulo: Atlas, 2014. Disponível em: https://integrada. minhabiblioteca.com.br/\#/books/9788522491483/. Acesso em: 02 Out. 2018.

. Sistemas de Informações Gerenciais-Estratégias-Táticas-Operacionais, $17^{\mathrm{a}}$ ed. São Paulo: Atlas, 2018. Disponível em: https://integrada. minhabiblioteca.com.br/\#/books/9788597015447/. Acesso em: 03 Out. 2018.

PADOVEZE, Clóvis Luís. Contabilidade gerencial: um enfoque em sistema de informação contábil. 7. ed. São Paulo: Atlas, 2010. Disponível em: https://integrada.minha biblioteca.com.br/\#/books/9788522486960/. Acesso em: 03 Set. 2018.

PINTO, Álvaro Vieira. O conceito de tecnologia. Rio de Janeiro: Contraponto, 2005.

REZENDE, Denis Alcides. Sistemas de informações organizacionais: guia prático para, projetos em cursos de administração, contabilidade e informática, $5^{\text {a }}$ ed. São Paulo: Atlas, 2013. Disponível em: https://integrada.minhabiblioteca.com.br/\#/books/9788522477838/. Acesso em: 04 Out. 2018.

SCHMIDT, Paulo; SANTOS, José dos, Martins, Marco Antônio dos Santos. Manual de Controladoria. São Paulo: Atlas, 2014. Disponível em: https://integrada. minhabiblioteca.com.br/\#/books/9788522491902/. Acesso em: 05 Out. 2018.

\section{Como citar este artigo (Formato ABNT):}

LIMA, Douglas Alexandre Sampaio de; MACEDO, Maria Erilúcia Cruz. Controladoria: A relevância da Tecnologia da Informação na qualidade dos relatórios contábeis.. Id on Line Rev.Mult. Psic., 2018, vol.12, n.42, Supl. 1, p. 688-702. ISSN: 1981-1179. 